\title{
Spatially variable synergistic effects of disturbance and additional nutrients on kelp recruitment and recovery
}

\section{Carnell, Paul. E* and Keough, Michael. J}

Department of Zoology, The University of Melbourne, Parkville, Victoria, 3010.

*pcarnell@unimelb.edu.au, mjkeough@unimelb.edu.au

Corresponding author:

Paul Carnell

(w)+6138344 4862

(m)+61 417054087

(f)+6138344 7909

Department of Zoology

The University of Melbourne

Parkville 3010

Victoria

Australia

Author Contributions: PC and MK designed the study, PC collected the data, PC and MK conducted the statistical analyses and wrote the manuscript. 


\section{Abstract}

2 Understanding the impact of multiple stressors on ecosystems is of pronounced importance,

3 particularly when one or more of those stressors is anthropogenic. Here we investigated the role of

4 physical disturbance and increased nutrients on reefs dominated by the canopy-forming kelp

5 Ecklonia radiata. We combined experimental kelp canopy removals and additional nutrient at three

6 different locations in a large embayment in temperate southeastern Australia. Over the following

7 winter recruitment season, Ecklonia recruitment was unaffected by increased nutrients alone, but

8 tripled at all sites where the canopy had been removed. At one site, the combination of disturbance

9 and increased nutrients resulted in more than four times the recruitment of the introduced kelp Undaria pinnatifida. Six months after disturbance, the proliferation of the Undaria canopy in the canopy removal and nutrient addition treatment negatively influenced the recovery of the native kelp Ecklonia. Given the otherwise competitive dominance of adult Ecklonia, this provides a mechanism whereby Undaria could maintain open-space for the following recruitment season. This interplay between disturbance, nutrients and the response of native and invasive species makes a compelling case for how a combination of factors can influence species dynamics.

Keywords: Multiple stressors; invasive species; resilience; Ecklonia radiata; Undaria pinnatifida 
17 As ecosystems come under pressure from both natural and anthropogenic stressors there is a pressing need to understand how multiple stressors interact. A stressor is defined here as the impact of any factor that adversely affects individual performance and impairs population growth rate through reduced survival, growth and/or reproduction (Wahl et al. 2011). Physical disturbance has long been recognised as a powerful driver of species diversity and community assemblages (Connell 1978; Sousa 1984; Dayton and Tegner 1984). Disturbances cause mortality, free up resources, allow ephemeral or opportunistic species to take advantage of the resultant conditions and allow for local changes in community structure, sometimes to different community states (Connell et al. 1997; Mumby et al. 2007). In temperate marine environments, physical disturbances play an important role on rocky reefs (Dayton et al. 1992, Reed et al. 2011), particularly when they alter the abundance of habitat-forming species.

Nutrient inputs are an important anthropogenic stressor in coastal environments (Worm et al. 2000, Berger et al. 2004, Korpinen et al. 2007a). Anthropogenic nutrient inputs or other changes in the nutrient regime can substantially alter ecosystem dynamics. These effects can stem from influences on recruitment (Steen 2004, Steen and Scrosati 2004), competitive and trophic interactions (Hemmi and Jormalainen 2002, Korpinen et al. 2007b). This can be facilitated, for example, by a negative response from a dominant species (Littler and Murray 1975; Brown et al. 1990; Doblin and Clayton 1995), positive responses by ephemeral and competitive species (Worm and Sommer 2000, Lotze and Worm 2002, Russell and Connell 2005), or a combination of these (Bellgrove et al. 1997, Steen 2004, Kraufvelin et al. 2006, Bulleri et al. 2012).

While single stressors can have important effects on their own, they often do not occur in isolation. Indeed, synergies between multiple stressors are of increasing concern (Hughes et al. 2003; Mora et al. 2007; Shears and Ross 2010; Falkenberg et al. 2012). Multiple stressors can influence species and community dynamics in a range of ways (Gross et al. 2005; Massad et al. 2013, Falkenberg et al. 
2013; Ross et al. 2013). These impacts can include changes in species diversity (Worm et al. 1999,

Worm et al. 2002, Korpinen et al. 2007b, Valdivia et al. 2008, Korpinen et al. 2010), the bloom of ephemeral species (Lotze and Worm 2002, Steen and Rueness 2004, Eriksson et al. 2007) or by changing top down and/or bottom up dynamics (Korpinen et al. 2007b, Korpinen and Jormalainen 2008). Despite recent increasing knowledge in this area, a recent review by Crain et al. (2008) highlighted the lack of field experiments testing multiple stressors in marine environments.

Our understanding of multiple stressors has also been limited in the range of species and ecosystems studied. Multiple stressors may have particularly strong consequences if they affect dominant species, which in turn influence a range of others. We have little knowledge of the effects on such species - ecosystem engineers - species significant because they modify abiotic conditions, provide habitat structures or essential ecosystem functions (Jones et al. 1994, Olff et al. 2009). On many temperate reefs, one group of brown algae, the kelps, play this role by influencing light, sedimentation and water flow (Eckman et al. 1989, Kennelly 1989, Wernberg et al. 2005). Kelp forests are highly productive and diverse ecosystems that have been impacted heavily by human activities in the past and are predicted to come under continuing pressure in the future (Steneck et al. 2002). How kelps themselves respond to multiple stressors will ultimately have consequences for a whole suite of associated species and a range of ecosystem services.

We tested how two stressors would influence kelp recruitment and recovery in southeastern Australia. Here, the native kelp Ecklonia radiata (hereafter Ecklonia) dominates the shallow sub-tidal reef assemblages and is an important ecosystem engineer; modifying both light and sedimentation to influence a range of algal species (Kennelly 1989, Wernberg et al. 2005, Smale et al. 2011). We tested the effects of disturbance and additional nutrients on kelp recruitment, and hypothesised that these two stressors would act synergistically to influence the native kelp recovery either directly or indirectly. We consider these two factors "stressors" as the disturbance itself causes direct mortality and subsequently this may influence Ecklonia recruitment through changed abiotic 
conditions. Nutrients can negatively influence brown algal reproduction (and therefore recruitment) or indirectly both factors have the potential to promote the proliferation of other species that negatively influence kelp recovery. We repeated the experiment at three sites specifically chosen for quite different background conditions, to see whether synergies were locally specific or consistent across a range of environments.

\section{Materials and Methods}

The range of environmental conditions exhibited on a relatively small spatial scale within Port Phillip Bay, a $2000 \mathrm{~km}^{2}$ embayment in southeastern Australia provides an ideal study area in which to test the spatial consistency of experimental outcomes. Three specific sites were chosen in Port Phillip Bay to test for spatial variation and consistency in the effects of disturbance and increased nutrients. These were St Leonards in the south west $\left(38^{\circ} 9^{\prime} 13.53^{\prime \prime S}, 144^{\circ} 43^{\prime} 41.87^{\prime \prime E}\right)$, Beaumaris in the north east $\left(37^{\circ} 59^{\prime} 55.91^{\prime \prime} \mathrm{S}, 1^{\circ} 5^{\circ} 1^{\prime} 54.77^{\prime \prime} \mathrm{E}\right)$ and Mornington in the south east $\left(38^{\circ} 14^{\prime} 34.35^{\prime \prime S}\right.$, $\left.145^{\circ} 1^{\prime} 33.27 " \mathrm{E}\right)$. The reefs at these sites are between $3-5 \mathrm{~m}$ depth and dominated by the kelp Ecklonia radiata. These sites differ in current speed, salinity (Lee et al. 2012) and aspect (which in Port Phillip Bay influences wave exposure), and were chosen to represent a known range of background environments in which Ecklonia canopy reefs occur, rather than to provide a random sample of Ecklonia reefs.

The experimental design consisted of an Ecklonia removal treatment (full canopy removal or canopy control) crossed with nutrient treatment (nutrient addition or nutrient control) in a fully factorial design with five replicate $1 \mathrm{~m}^{2}$ plots per treatment. This design was repeated at each site. Only Ecklonia was cleared from the canopy removal plots. 'Clearing' was achieved by cutting the stipe just above the holdfast, a technique used previously with no artefacts (Kennelly 1987b). Nutrients were added by attaching fine $(0.5 \mathrm{~mm} \times 0.5 \mathrm{~mm})$ mesh bags containing $1 \mathrm{~kg}$ of Osmocote Plus $^{\top \mathrm{TM}}$ (Everris Australia Pty Ltd) 3-4 month release $(17 \% \mathrm{~N}, 5 \% \mathrm{~K}, 8 \% \mathrm{P})$ to a star picket hammered into rock in the centre of the $1 \mathrm{~m}^{2}$ plots. The nutrient bags hung $5 \mathrm{~cm}$ from the rock surface and 
extended $20 \mathrm{~cm}$ up the star picket. The nutrient bags were changed once after 3-4 months. After removing the nutrient bags, the amount of solid product that had not dissolved was dried and weighed to calculate an average release rate of nitrogen per day over the treatment period (Table 1). This technique is in line with recommendations by Worm et al. (2000) and has been used in previous studies in which either lower volumes of fertiliser (Russell and Connell 2005) or more localised nutrient delivery techniques (Morris et al. 2007) resulted in elevated nitrogen levels $\left(\mathrm{NO}_{3}\right.$, $\mathrm{NH}_{4}$ ) above the background levels. There was no difference in the amount of fertiliser released over the experimental period (dry mass of Osmocote weighed after retrieval) between sites $\left(F_{(2,22)}=0.79, p=0.47\right)$ or between canopy removal treatments $\left(F_{(1,22)}=2.16, p=0.16\right)$.

Initial plot surveys were carried out in February-March 2012 of the Ecklonia canopy percentage cover and the number of juvenile and adult plants (stages 2 and 3, as defined by Kirkman 1981). These values varied between sites (Table 1, \% cover: St Leonards>Beaumaris>Mornington $\left(F_{(2,48)}=33.23, p=<0.001\right)$, number: Beaumaris=Mornington $>$ St Leonards $\left.\left(F_{(2,48)}=12.92, p=<0.001\right)\right)$, but not between treatments (Nutrients: \% cover, $F_{(1,48)}=0.52, p=0.473$, number $F_{(1,48)}=1.61, p=0.211$; Ecklonia Removal: \% cover, $\mathrm{F}_{(1,48)}=0.33, \mathrm{p}=0.568$, number $\left.\mathrm{F}_{(1,48)}=1.97, \mathrm{p}=0.167\right)$, or treatments assigned to plots at each site (\% cover $\left(F_{(2,48)}=0.58, p=0.562\right)$, number $\left(F_{(2,48)}=1.17, p=0.319\right)$ ). The experimental manipulations were carried out in April 2012 (Austral autumn), just prior to the peak recruitment of Ecklonia sporophytes over winter (Kennelly 1987a). The experiment was monitored at three (July 2012) and six months (October 2012) post-treatment via photos for total Ecklonia percentage cover and counts of Ecklonia recruits (stage 1, as defined by Kirkman (1981)). Recruits and juveniles (at three months) and adults (6 months, sporophylls present) of the non-native kelp Undaria pinnatifida were also counted in plots where they appeared. Photographs were analysed for the percentage cover of Ecklonia and Undaria using the image analysis software Image J $1.45 \mathrm{~s}$ (Abramoff et al. 2004). 
Analysis of the initial survey data and Ecklonia recruitment data was carried out using a factorial ANOVA, with three fixed factors; site, Ecklonia removal treatment and nutrient addition treatment.

Sites were chosen specifically to reflect several very different environmental conditions (species assemblages and environmental variables) around Port Phillip Bay and were not a random sample of any "population" of sites. As such, they were considered as a fixed, not a random effect. As Undaria only recruited into plots at Beaumaris, site was not included as a factor in this analysis, which was run as a two-factor ANOVA. Count data were log transformed and percentage cover data arcsine transformed to improve normality.

\section{Results}

At the three month survey (Austral winter), the recruitment of Ecklonia radiata stage 1 recruits varied markedly between sites and with the removal of the Ecklonia canopy (Table 2). There was much higher overall recruitment in plots at St Leonards $(24.1 \pm 13.5)$ than Beaumaris $(4.8 \pm 1.5)$ and Mornington (4.5 \pm 2.0$)$. There was also an overall effect of the canopy removal treatment, with approximately three times more Ecklonia recruits in plots where all the Ecklonia had been removed previously (controls $5 \pm 4.0$, removals $17.3 \pm 11.2$ ). After six months (Austral Spring), the relationship was more complex, with a significant interaction between site and canopy removal (Table 2), with a six-fold increase in recruitment at St Leonards when Ecklonia was removed, a five-fold increase at Mornington, and only a $60 \%$ increase over controls at Beaumaris (Figure 1). At both time points Ecklonia recruitment was not influenced by nutrients, either alone or in combination with removals (Table 2). The introduced kelp Undaria pinnatifida recruited naturally into plots, but only at Beaumaris. No Undaria was observed within $2 \mathrm{~km}$ of the Mornington or St Leonards sites, but it was observed in low abundances on the reef at Beaumaris. There was a strong synergistic effect of kelp canopy treatment and nutrient addition, with much higher recruitment of Undaria into plots where Ecklonia had been removed and nutrients added, at both the three and six month time points at Beaumaris 
(Figure 2, Table 3). At three months, the recruits and juveniles in the Ecklonia removal plots were recorded at average densities of $33.6 \pm 8.2 \mathrm{~m}^{-2}$ in the nutrient addition, compared to $8.2 \pm 2.3 \mathrm{~m}^{-2}$ in the nutrient control. Numbers were lowest in the Ecklonia canopy control plots with $1.6 \pm 0.5$ plants $\mathrm{m}^{-2}$ in nutrient control plots and $1.8 \pm 1.5 \mathrm{~m}^{-2}$ in nutrient addition plots. Undaria recruits grew rapidly and many were mature by 6 months.

The percentage cover of Undaria at six months also demonstrated a strong synergistic response, dominating plots where Ecklonia removal and nutrient additions were combined (Fig. 3b, Table 3). Conversely, for Ecklonia the combined treatment effect resulted in the lowest percentage cover. (Fig. 3a, Table 3).

\section{Discussion}

Recruitment of the native kelp Ecklonia radiata was enhanced by the removal of adult plants at all sites, but was unaffected by additional nutrients. Initially, Ecklonia responded in a similar way at all three sites, but differences between Beaumaris and the other sites emerged after 6 months. The surprising result was that the introduced kelp Undaria pinnatifida recruited in substantial numbers at one site, with highest densities and cover in plots that experienced both the loss of native kelp canopy and the addition of nutrients. This is one of only a handful of cases to clearly demonstrate how the synergistic effects of two separate stressors can lead to the proliferation of an invasive species. Moreover, the pattern was observed at the time of recruitment of Undaria (three month survey) and when the plants themselves became reproductive (six month survey). Importantly, an intact Ecklonia canopy appears to have few Undaria recruits, which is consistent with other work (Valentine and Johnson 2003). However, while there was some increase in Undaria recruitment where Ecklonia had been removed, it was only in the presence of additional nutrients that Undaria became dominant. and with the removal of the Ecklonia canopy. While the recruitment of Ecklonia and other kelps can 
be highly variable, particularly between sites and regions (Kennelly and Underwood 1993), our pattern of increased recruit numbers in cleared patches is concordant with a number of previous studies (Kennelly 1987a; Kennelly 1987b). Dense kelp canopies are able to reduce light levels low enough to reduce understorey gametogenesis and growth (Dayton et al. 1992). Ecklonia gametophytes require a daily quantum dose of at least $40 \mathrm{cE} \mathrm{M}{ }^{-2}$ to reproduce(Novaczek 1984), but under a canopy receive roughly $1-5 \%$ of available light (Wernberg et al. 2005). Thus, the loss of a kelp canopy and resultant spike in light levels can then stimulate kelp gametogenesis and growth (Luning 1980, Luning and Neushul 1978). However, despite this effect of light, increased recruitment post-disturbance is not always observed.

Based on a considerable body of work across temperate Australia, the variability in recruitment between sites or studies is believed to be due to a complex relationship between the negative impact of turf forming algal species (Kennelly 1987a; Gormon and Connell 2009; Connell and Russell 2010), and the net positive or negative effect of the adult kelp canopy on recruits (Irving and Connell 2006; Toohey and Kendrick 2007). The substantially higher recruitment of Ecklonia seen at St Leonards suggests that while the treatment effects were consistent, a site-specific factor resulted in higher recruitment overall at St Leonards.

The difference in response of Undaria (positive) and Ecklonia (neutral) to additional nutrients could result from the difference in ammonium uptake between the two species (Paling 1991, Campbell 1999). Interestingly, additional nutrients in conjunction with canopy removal did not influence Ecklonia recruitment in the way that has been shown elsewhere (Russell and Connell 2005). A negative response was expected, because turf-forming species that inhibit kelp recruitment (Kennelly 1987a; Connell and Russell 2010) respond positively to both disturbance and nutrients 187 (Russell and Connell 2005; Falkenberg et al. 2012). However, in the present study, while various turf species were present (unpublished data), they obviously did not proliferate enough to cause a difference between nutrient treatments at the sites studied. 
Importantly, six months after initial disturbance, Mornington and St Leonards continued to exhibit higher recruitment of Ecklonia into plots cleared of the canopy than controls, a trend that was weaker at Beaumaris. The disappearance of a strong canopy clearance effect at Beaumaris by six months seemed to stem from the fact that recruit numbers remained stable in removal plots at Beaumaris, in contrast to St Leonards and Mornington where they continued to increase. This indicates a site-specific change in the abiotic or biotic influence on recruits in the removal treatment at Beaumaris between three and six months. Intriguingly, this time frame coincides with the proliferation of the Undaria canopy at this site. However, without testing specifically for the effect of an Undaria canopy on Ecklonia recruits, we cannot separate this explanation from other factors that might cause this effect.

The lower recruitment of Ecklonia into cleared plots at Beaumaris has potentially significant implications for the invasion dynamics of Undaria on this reef. In general, a perennial life history should favour the competitive dominance of Ecklonia compared to the annual Undaria. Valentine and Johnson (2003) found that while disturbance to the native canopy resulted in increased levels of the Undaria sporophyte, the native canopy at one site but not the other was able to recover sufficiently in the following years to exclude Undaria. However, while Ecklonia showed significant signs of recovery six months after removal in our nutrient control treatment ( $16 \%$ cover), this was in stark contrast to where nutrients were added ( $2 \%$ cover). Given that the final survey was at the end of spring (the highest growth period) and that Ecklonia growth slows dramatically over summer (Kirkman 1984), we would expect the percentage cover of Ecklonia to be similar at the time of winter recruitment the following year. This open space would then allow for the recruitment of Undaria the following year. Our data suggests that where disturbance and additional nutrients are combined, this could tip the balance in favour of Undaria, by dramatically increasing Undaria recruitment and growth, slowing Ecklonia recovery. 
Our result does raise two interesting questions about the sudden appearance of Undaria. First, why did Undaria appear in such numbers at Beaumaris, but was not observed at Mornington or St Leonards? In general, Undaria is more common in the northern half of Port Phillip Bay (Primo et al. 2010) which, despite its high reproductive output (Schiel and Thompson 2012), could reflect its poor natural dispersal potential (Forrest et al. 2000) or alternatively, result from unsuitable recruitment conditions elsewhere in the bay. This means that sites with no adults are much less likely to receive propagules, let alone in large numbers. We were therefore surprised by the proliferation of Undaria at Beaumaris given its apparent absence in preceding years (Primo et al. 2010).

The second interesting question centres on the requirement of a substantial nutrient spike to promote high recruitment of Undaria. As a water body, Port Phillip Bay receives substantial nutrient inputs but also exhibits high denitrification efficiency, so levels of dissolved nutrients are generally low and algal blooms rare (Heggie et al. 1999, Murray and Parslow 1999). The ability of Undaria to maintain canopy space at Beaumaris may depend not only on its ability to suppress Ecklonia, but also conditions favouring its own recruitment and growth. Morelissen et al. (2013) recently demonstrated in a lab setting how both higher light levels and increased nutrients were important for development and growth of young Undaria sporophytes, supporting the results from our field study. High nutrient levels may occur only briefly and in certain areas after big rainfall events; we therefore speculate that the coincidence of these events with high Undaria propagule numbers might be important for the persistence of this annual species across years.

This study and others that have experimentally added nutrients into marine systems are providing a much clearer picture of both individual species and system responses to elevated nutrients (Russell \& Connell 2005; Korpinen et al. 2007a, Korpinen et al. 2007b, Morris et al. 2007; O’Brien et al. 2010). It is now clear that the combination of disturbance and increased nutrient levels have the ability to alter community dynamics in a number of different ways (O'Brien et al. 2009, Massad et al. 2013). 

decrease ecosystem recovery from disturbance (Russell and Connell 2005; Kraufvelin et al. 2006, Falkenberg et al. 2012). While the impact that additional nutrients can have is clear, it is also apparent that the effect between sites or studies can be inconsistent (Morris and Keough 2003, Bulleri et al. 2012). By continuing to build upon this body of work, we will be able to start to generalise species and community responses to nutrient inputs.

While this study provides evidence on how disturbance and nutrients can have unexpected consequences, in this case favouring an invasive species, we are now building up an increasing number of experimental studies on a range of factors that facilitate invasive species. Whether this is through increased propagule pressure (Clark and Johnston 2009), heavy metal pollution (McKenzie et al. 2012; Piola and Johnston 2008) or physical disturbance itself (Valentine and Johnson 2003), as ecosystems come under more and more pressures we are seeing their resilience become eroded. Understanding if and how multiple stressors act synergistically is an urgent concern, particularly as most systems are often dealing with multiple environmental and anthropogenic stressors.

\section{Acknowledgements}

We thank R. Saaristo, P. Crockett, P. Gilmour, C. Jung, R. Chisholm, C. Taylor, H. Wooton and B. Hull for their invaluable field assistance. We also thank K. Mossop, A. O'Brien and three anonymous reviewers for comments that greatly improved the manuscript. This study was funded by an Australian Research Council grant to MJK, a Holsworth Wildlife Research Endowment to PEC, the Jasper Loftus-Hills award to PEC and an Australian Postgraduate Award to PEC. 
Bellgrove A, Clayton MN, Quinn GP (1997) Effects of secondarily treated sewage effluent on intertidal macroalgae recruitment processes. Mar Freshw Res 48: 137-146

Berger R, Bergstrom L, Graneli E, Kautsky L (2004). How does eutrophication affect different life stages of Fucus vesiculosus in the Baltic Sea? A conceptual model. Hydrobiologia 514: 243-248.

Bulleri F, Russell BD, Connell SD (2012) Context-dependency in the effects of nutrient loading and consumers on the availability of space in marine rocky environments. PLoS ONE 7: 1-9

Campbell, S. J. 1999. Uptake of ammonium by four species of macroalgae in Port Phillip Bay, Victoria Australia. Mar Freshw Res 50:515-22

Campbell SJ, Bité JS, Burridge TR (1999) Seasonal patterns in the photosynthetic capacity, tissue pigment and nutrient content of different development stages of Undaria pinnatifida (Phaeophyta: Laminariales) in Port Phillip Bay, South-Eastern Australia. Botanica Marina 42: 231-242

277 Clark GF, Johnston EL (2009) Propagule pressure and disturbance interact to overcome biotic resistance of marine invertebrate communities. Oikos 118: 1679-1686 disturbance at several scales in space and time. Ecol Mono 67: 461-488 
Dayton PK, Tegner MJ, Parnell PE, Edwards PB (1992) Temporal and spatial patterns of disturbance and recovery in a kelp forest community. Ecol Mono 62: 421-445

Doblin M, Clayton MN (1995) Effects of secondarily treated sewage effluent on the early life history stages of two species of brown macroalgae: Hormosira banksii and Durvillaea potatorum. Mar Biol $122: 689-698$

Eckman JE, Duggins DO, Sewell AT (1989) Ecology of understory kelp environments I. Effects of kelps on flow and particle transport near the bottom. J Exp Mar Biol Ecol 129: $173-188$ resource and consumer control of bloom-forming macroalgae. Oikos 116: 1211-1219 synergistic effects of local and global pollution in kelp forests. PLOS ONE 7: 1-7 producers: implications for competitive interactions under enriched $\mathrm{CO}_{2}$ and nutrient regimes. in the spread of Undaria pinnatifida (Laminariales, Phaeophyceae). Phycologia 39, 547-553 
Gross KL, Mittelbach GG, Reynolds HL (2005) Grassland invasibility and diversity: responses to nutrients, seed input, and disturbance. Ecology 86: 476-486

Heggie DT, Skyring GW, Orchardo J, Longmore AR, Nicholson GJ, Berelson WM (1999) Denitrification and denitrifying efficiencies in sediments of Port Phillip Bay: direct determinations of biogenic $\mathrm{N}_{2}$ and N-metabolite fluxes with implications for water quality. Mar Freshwater Res 50: 589-596

Hemmi A, Jormalainen V (2002) Nutrient enhancement increases performance of a marine herbivore via quality of its food alga. Ecology 83: 1052-1064 MJ, Lewis JA, Lockett MM, Mays N, McArthur MA, O'Hara TD, Poore GCB, Ross DJ, Storey MJ, Watson JE, Wilson RS (2004) Introduced and cryptogenic species in Port Phillip Bay, Victoria,

Hughes TP, Baird AH, Bellwood DR, Card M, Connolly SR, Folke C, Grosberg R, Hoegh-Guldberg O, Jackson JBC, Kleypas J, Lough JM, Marshall P, Nyström M, Palumbi SR, Pandolfi JM, Rosen B \& Roughgarden J (2003) Climate change, human impacts, and the resilience of coral reefs. Science 301: 929-933 Irving AD, Connell SD (2006) Physical disturbance by kelp abrades erect algae from the understorey. Mar Ecol Prog Ser 324:127- 137 Jones CG, Lawton JH, Shachak M (1994) Organisms as Ecosystem engineers. Oikos 69: 373-386 Kennelly SJ (1987a) Physical disturbances in an Australian kelp community .1. Temporal effects. Mar Ecol Prog Ser 40: 145-153 species due to differences in kelp cover. Mar Ecol Prog Ser 40: 155-165 
Kennelly SJ (1989) Effects of kelp canopies on understorey species due to shade and scour. Mar Ecol

Kennelly SJ, Underwood AJ (1993) Geographic consistencies of effects of experimental physical disturbance on understorey species in sublittoral kelp forests in central New South Wales. J Exp Mar Biol Ecol 168: 35-58

Kirkman $\mathrm{H}$ (1981) The first year in the life history and the survival of the juvenile marine macrophyte, Ecklonia radiata (Turn.) J. Agardh. J Exp Mar Biol Ecol 55: 243-254

Kirkman H (1984) Standing stock and production of Ecklonia radiata (C.Ag.) J. Agardh. J Exp Mar Biol Ecol 76, 119-130 Macroalgal communities face the challenge of changing biotic interactions: review with focus on the Baltic Sea. Ambio 36: 203-211

Korpinen S, Jormalainen V (2008a) Grazing and nutrients reduce recruitment success of Fucus

Korpinen S, Jormalainen V, Honkanen T (2007a) Effects of nutrients, herbivory, and depth on the macroalgal community in the rocky sublittoral. Ecology 88: 839-852

Korpinen S, Jormalainen V, Honkanen T (2007b) Bottom-up and cascading top-down control of macroalgae along a depth gradient. Journal of Experimental Marine Biology and Ecology 343:52-63

Korpinen S, Jormalainen V, Pettay E (2010) Nutrient availability modifies species abundance and community structure of Fucus-associated littoral benthic fauna. Mar Environ Res 70: 283-292 
351 Lee RS, Black KP, Bosserel C, Greer D (2012) Present and future prolonged drought impacts on a

352 large temperate embayment: Port Phillip Bay, Australia. Ocean Dynam 62: 907-922

353 Littler MM, Murray SN (1975) Impact of sewage on the distribution, abundance and community

354 structure of rocky intertidal macro-organisms. Mar Biol 30: 277-291

355 Luning K (1980) Critical light levels and temperature regulating the gametogenesis of three Laminaria 356 species (Phaeophyceae). J of Phyc 16, 1-15

357 Luning K, Neushul M (1978) Light and temperature demands for growth and reproduction for Laminaria gametophytes in southern and central California. Mar Biol

Massad TJ, Balch JK, Davidson EA, Brando PM, Mews CL, Porto P, Quintino RM, Vieira SA, Marimon BH Jr, Trumbore SE (2013) Interactions between repeated fire, nutrients, and insect herbivores affect the recovery of diversity in the southern Amazon. Oecologia 172:219-229 of a marine invader. J App Ecol 49: 767-773

Mora C, Metzger R, Rollo A, Myers, RA (2007) Experimental simulations about the effects of overexploitation and habitat fragmentation on populations facing environmental warming. Proc $R$ Soc B Biol Sci 274:1023-1028

Morris L, Keough MJ (2003) Variation in the response of intertidal infaunal invertebrates to nutrient additions: field manipulations at two sites within Port Phillip Bay, Australia. Marine Ecology-Progress Series 250: 35-49

Morris L, Jenkins G, Hatton D, Smith T (2007) Effects of nutrient additions on intertidal seagrass

371 (Zostera muelleri) habitat in Western Port, Victoria, Australia. Mar Freshw Res 58: 666-674 
Murray AG, Parslow JS (1999) Modelling of nutrient impacts in Port Phillip Bay - a semi-enclosed marine Australian ecosystem. Mar Freshwater Res 50: 597-611

Novaczek I (1984) Response of Ecklonia radiata (Laninariales) to light at $15^{\circ} \mathrm{C}$ with reference to the porewater nutrient enrichment, bioturbation and sediment characteristics on benthic assemblages in sandy sediments. J Exp Mar Biol Ecol 371: 51-59

O'Brien AL, Morris L, Keough, MJ (2010) Multiple sources of nutrients add to the complexities of predicting marine benthic community responses to enrichment. Mar Freshw Res 61: 1388-1398 Olff H, Alonso D, Berg MP, Eriksson BK, Loreau M, Piersma T, Rooney N (2009). Parallel ecological networks in ecosystems. Phil Trans Roy Soc B 364: 1755-1779.

Lotze HK, Worm B (2002) Complex interaction of ecological and climatic controls on macroalgal recruitment. Limnology and Oceanography 47: 1734-1741

Paling El (1991) The relationship between nitrogen cycling and productivity in macroalgal stands and seagrass meadows. Ph.D thesis. University of Westem Australia.

Piola, RF, Johnston EL (2008) Pollution reduces native diversity and increases invader dominance in marine hard-substrate communities. Divers. \& Distrib 14: 329-342 pinnatifida (Phaeophyceae, Laminariales) in Port Phillip Bay (Victoria, Australia). Biol Invas 12: 30813092 
Ross DJ, Longmore AR, Keough MJ (2013) Spatially variable effects of a marine pest on ecosystem function. Oecologia 172: 525-538

Russell BD, Connell SD (2005) A novel interaction between nutrients and grazers alters relative dominance of marine habitats. Mar Ecol Prog Ser 289: 5-11 pinnatifida on shallow reefs in Southern New Zealand. J Exp Mar Biol Ecol 434-435: 25-33.

Shears NT, Ross PM (2010) Toxic cascades: multiple anthropogenic stressors have complex and unanticipated interactive effects on temperate reefs. Ecol Lett 13: 1149-1159

Smale DA, Wernberg T, Vance T (2011) Community development on subtidal reefs in a biodiversity hotspot: the influences of wave energy and the stochastic recruitment of a dominant kelp. Marine Biology, 158: 1757-1766

412 (Phaeophyceae: Fucales) germlings: effects of settlement density, nutrient concentration, and temperature. Mar Biol 144: 61-70

Steen H (2004) Interspecific competition between Enteromorpha (Ulvales: Chlorophyceae) and Fucus (Fucales: Phaeophyceae) germlings: effects of nutrient concentration, temperature, and settlement density. Mar Ecol Progr Ser 278: 89-101

417 Steneck RS, Graham MH, Bourque BJ, Corbett B, Erlandson JM, Estes JA, Tegner MJ (2002) Kelp forest ecosystems: biodiversity, stability, resilience and future. Environ Conserv 29: 436-459 
419 Toohey BD, Kendrick GA (2007) Survival of juvenile Ecklonia radiata sporophytes after canopy loss. J

420 Exp Mar Biol Ecol 349: 170-182

421 Valdivia N, Stehbens JD, Hermelink B, Connell SD, Molis, M. \& Wahl, M. (2008). Disturbance

422 mediates the effects of nutrients on developing assemblages of epibiota. Aust Ecol 33: 951-962

423 Valentine JP, Johnson CR (2003) Establishment of the introduced kelp Undaria pinnatifida in

424 Tasmania depends on disturbance to native algal assemblages. J Exp Mar Biol Ecol 295: 63-90

425 Wahl M, Jormalainen V, Eriksson BK, Coyer J A, Molis M, Schubert H, Dethier M, Karez R, Kryse I,

426 Lenz M, Pearson G, Rohde S, Wikstrom SA, Olsen JL (2011). Stress ecology in Fucus: abiotic, biotic,

427 and genetic interactions. In Lesser, M. [Ed.] Advances in Marine Biology, Vol 59. Elsevier Academic

428 Press Inc, San Diego, California, pp. 37-105.

429 Wernberg T, Kendrick GA, Toohey BD (2005) Modification of physical environment by an Ecklonia

430 radiata (Laminariales) canopy and its implications for associated foliose algae. Aqua Ecol 39: 419-430

431 Worm B, Reusch TBH, Lotze HK (2000) In situ nutrient enrichment: Methods for marine benthic

432 ecology. Int Rev Hydrob 85: 359-375

433 Worm B, Lotze H K, Bostrom C, Engkvist R, Labanauskas V, Sommer U (1999) Marine diversity shift

434 linked to interactions among grazers, nutrients and propagule banks. Mar Ecol Prog Ser 185: 309-314

435 Worm B, Lotze HK, Hillebrand H, Sommer U (2002) Consumer versus resource control of species

436 diversity and ecosystem functioning. Nature $417: 848-851$

437 Worm B, Sommer U (2000) Rapid direct and indirect effects of a single nutrient pulse in a seaweed-

438 epiphyte-grazer system. Marine Ecology Progress Series 202: 282-288 
Table 1 Data on initial site surveys of Ecklonia percent cover and initial density. The calculated average daily release of Nitrogen from the nutrient bags post retrieval is also presented. Values are means \pm SEM

\begin{tabular}{|lccc|}
\hline Site & $\begin{array}{c}\text { Average initial } \\
\text { \% cover of Ecklonia }\end{array}$ & $\begin{array}{c}\text { Average initial Ecklonia } \\
\text { sporophytes } \mathbf{~ m}^{-2}\end{array}$ & $\begin{array}{c}\text { Average N release } \\
\text { per day }(\mathbf{g})\end{array}$ \\
\hline St Leonards & $92.9_{ \pm} 1.9$ & $13.5 \pm 2.0$ & $1.21 \pm 0.18$ \\
Beaumaris & $83.0_{ \pm} 4.3$ & $20.3 \pm 1.5$ & $1.24 \pm 0.12$ \\
Mornington & $69.7 \pm 4.8$ & $19.8 \pm 2.1$ & $1.08_{ \pm} 0.13$ \\
\hline
\end{tabular}


Table 2 Three way ANOVA table of the effect of Site, Ecklonia Removal and Nutrient Addition on the natural log transformed number of Ecklonia recruits

\begin{tabular}{|lcccccc|}
\hline & \multicolumn{3}{c}{ 3 months } & \multicolumn{3}{c|}{$\mathbf{6}$ months } \\
\hline Source of variation & $\mathbf{d f}$ & $\mathbf{M S}$ & $\mathbf{P}$ & $\mathbf{d f}$ & $\mathbf{M S}$ & $\mathbf{P}$ \\
\hline Site (S) & 2 & 7.634 & $\mathbf{0 . 0 0 0}$ & 2 & 5.103 & $\mathbf{0 . 0 0 2}$ \\
Ecklonia Treatment (ET) & 1 & 12.842 & $\mathbf{0 . 0 0 0}$ & 1 & 26.431 & $\mathbf{0 . 0 0 0}$ \\
Nutrient Treatment (NT) & 1 & 0.032 & 0.823 & 1 & 0.003 & 0.947 \\
$\mathrm{~S}^{*}$ ET & 2 & 0.934 & 0.238 & 2 & 2.526 & $\mathbf{0 . 0 3 6}$ \\
$\mathrm{S}^{*} \mathrm{NT}$ & 2 & 0.246 & 0.680 & 2 & 0.335 & 0.625 \\
ET ${ }^{*} \mathrm{NT}$ & 1 & 0.103 & 0.688 & 1 & 1.678 & 0.130 \\
$\mathrm{~S}^{*} \mathrm{ET}{ }^{*} \mathrm{NT}$ & 2 & 0.491 & 0.465 & 2 & 1.024 & 0.245 \\
Error & 48 & 0.631 & & 48 & 0.706 & \\
\hline
\end{tabular}


Table 3 Two way ANOVA table of the effect Ecklonia removal treatment and nutrient addition at Beaumaris on: the natural log transformed number of Undaria recruits and juveniles at 3 months; Undaria adults at 6 months; the arcsine transformed percentage cover of Undaria at 6 months; and Ecklonia at 6 months

\begin{tabular}{|c|c|c|c|c|c|c|c|c|c|}
\hline & & \multicolumn{2}{|c|}{3 M \# Undaria } & \multicolumn{2}{|c|}{6 M \# Undaria } & \multicolumn{2}{|c|}{6 M \% Undaria } & \multicolumn{2}{|c|}{6 M \% Ecklonia } \\
\hline Source & df & MS & $\mathbf{P}$ & MS & $\mathbf{P}$ & MS & $\mathbf{P}$ & MS & $\mathbf{P}$ \\
\hline Ecklonia Treatment (ET) & 1 & 19.712 & 0.000 & 10.806 & 0.000 & 1.296 & 0.002 & 3.441 & 0.000 \\
\hline Nutrient Treatment (NT) & 1 & 1.450 & 0.135 & 2.512 & 0.031 & 0.248 & 0.117 & 0.089 & 0.017 \\
\hline NT *ET & 1 & 3.328 & 0.030 & 2.120 & 0.045 & 0.425 & 0.046 & 0.094 & 0.015 \\
\hline Error & 16 & 0.587 & & 0.446 & & 0.090 & & 0.013 & \\
\hline
\end{tabular}


Fig. 1 The mean $\left( \pm\right.$ SEM) natural logged number of the native kelp Ecklonia radiata recruits $\mathrm{m}^{-2}$ at the three experimental sites and Ecklonia removal treatment (Control or Removal) at 6 months post treatment. Open bars = canopy control, shaded bars = canopy removal

Fig. 2 Abundance of Undaria pinnatifida at Beaumaris after 6 months, showing synergistic effect of canopy removal and nutrient addition (shaded). The bars show the mean ( \pm SEM) natural logged number of adults $\mathrm{m}^{-2}$. Open bars = ambient nutrients, shaded bars = nutrient addition

Fig. 3 Percentage cover of a Ecklonia radiata and $\mathbf{b}$ Undaria pinnatifida at Beaumaris after 6 months in the Ecklonia removal treatments and nutrient addition treatments. The bars show the mean $( \pm \mathrm{SEM})$ percentage cover. Open bars = ambient nutrients, shaded bars $=$ nutrient addition 
Fig. 1

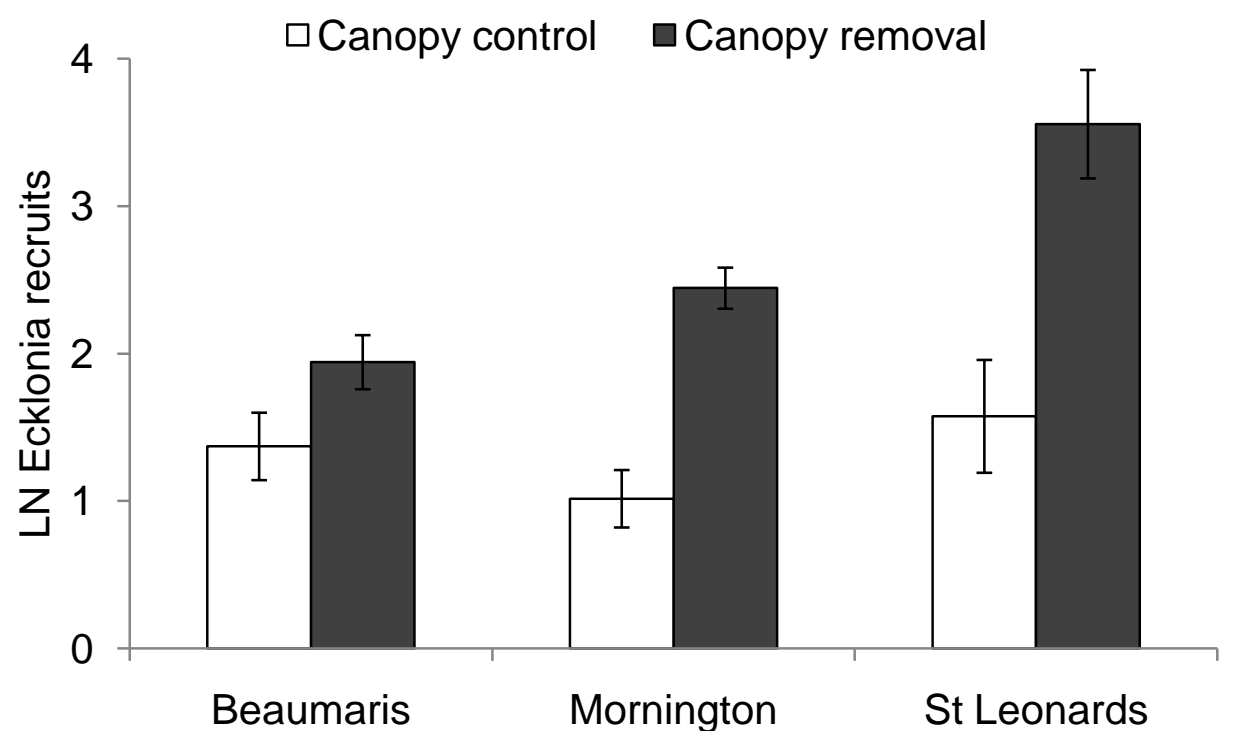


Fig. 2

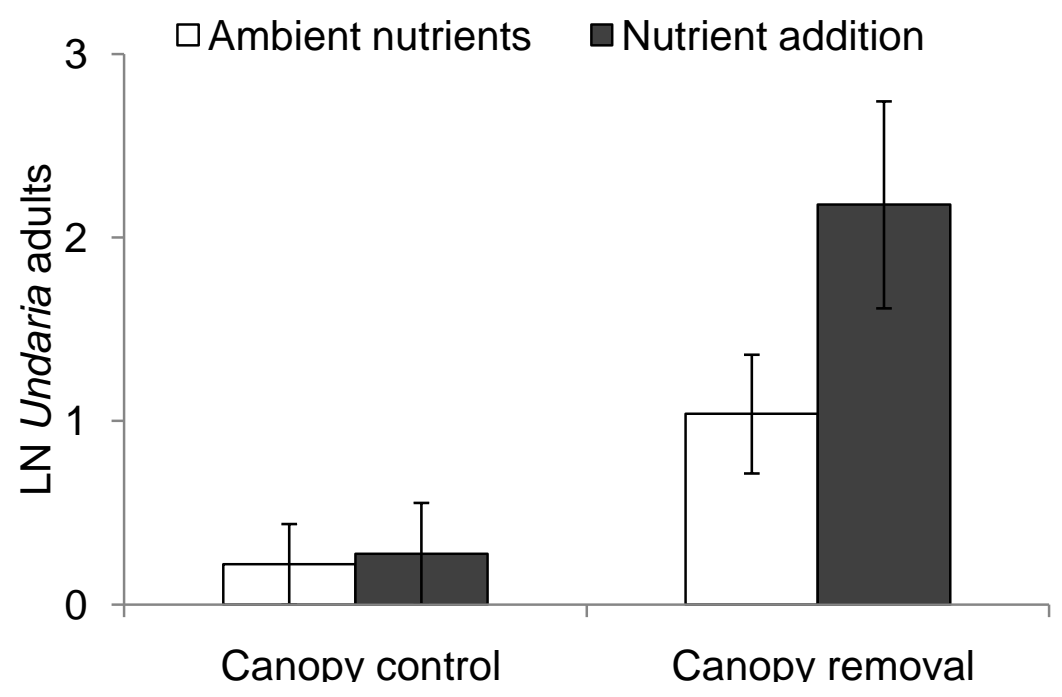


Fig. 3

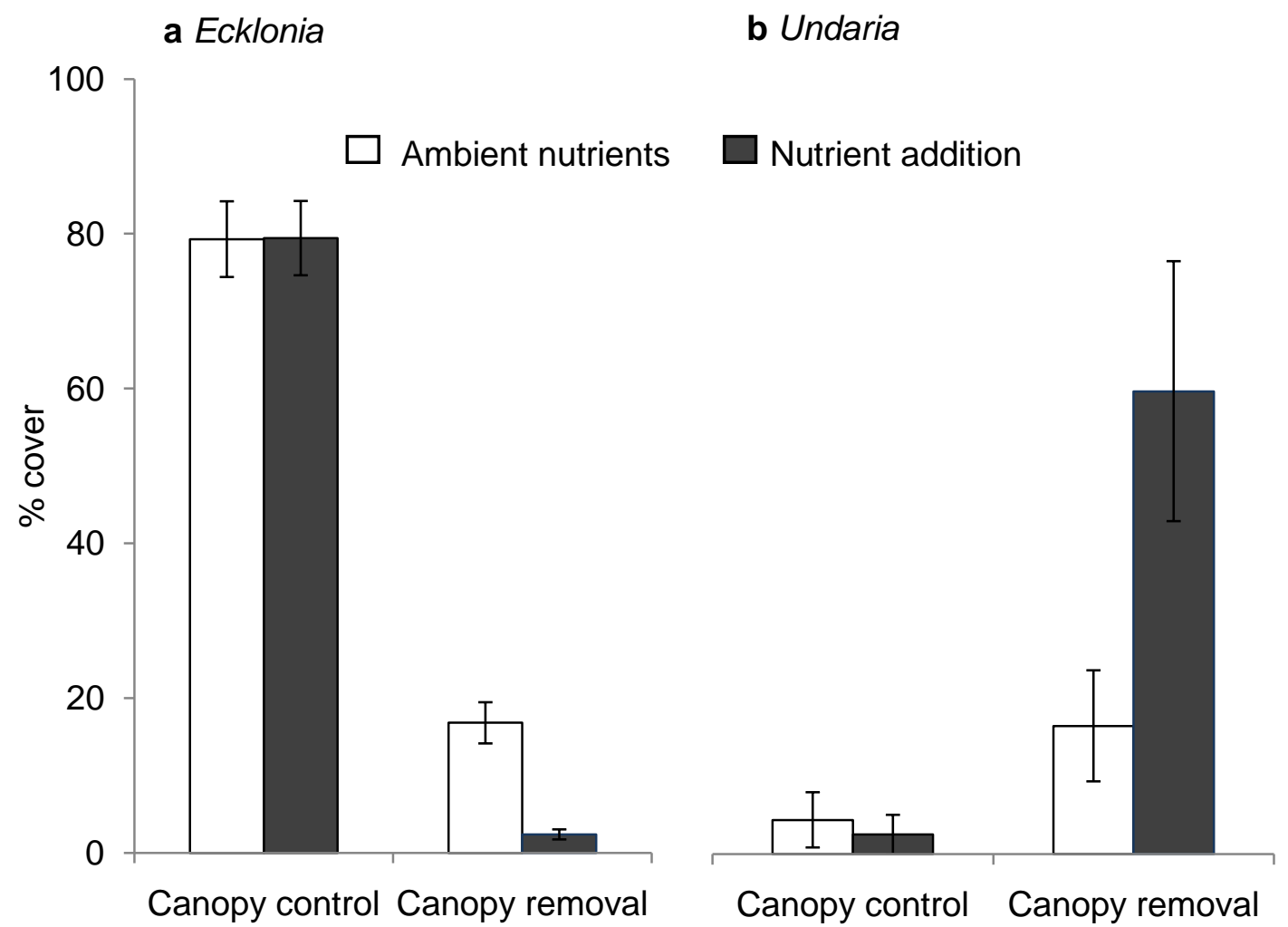




\section{University Library}

\section{- M M I N E R VA A gateway to Melbourne's research publications}

Minerva Access is the Institutional Repository of The University of Melbourne

Author/s:

Carnell, PE;Keough, MJ

Title:

Spatially variable synergistic effects of disturbance and additional nutrients on kelp recruitment and recovery

\section{Date:}

2014-05-01

\section{Citation:}

Carnell, P. E. \& Keough, M. J. (2014). Spatially variable synergistic effects of disturbance and additional nutrients on kelp recruitment and recovery. OECOLOGIA, 175 (1), pp.409-416. https://doi.org/10.1007/s00442-014-2907-9.

Persistent Link:

http://hdl.handle.net/11343/282693 